\title{
Export is not enough: nutrient cycling and carbon sequestration
}

\author{
Anand Gnanadesikan ${ }^{1, *}$, Irina Marinov ${ }^{2}$ \\ ${ }^{1}$ Geophysical Fluid Dynamics Laboratory, National Oceanic and Atmospheric Administration, 201 Forrestal Rd., Princeton, \\ New Jersey 08540, USA \\ ${ }^{2}$ Woods Hole Oceanographic Institution, 266 Woods Hole Rd., Woods Hole, Massachusetts 02543, USA
}

\begin{abstract}
The question of whether ocean iron fertilization (OIF) can yield verifiable carbon sequestration is often cast in terms of whether fertilization results in enhanced particle export. However, model studies show that oceanic carbon storage is only weakly related to global particle export - depending instead on an increase in the carbon associated with the pool of remineralized nutrients. The magnitude of such an increase depends on circulation, stoichiometric ratios and gas exchange. We argue that this puts serious challenges before efforts to properly credit OIF that must be taken into account at the design stage.
\end{abstract}

KEY WORDS: Ocean iron fertilization · Preformed nutrients · Carbon sequestration

\section{ROLE OF NUTRIENTS IN THE CARBON CYCLE}

One of the most puzzling facts in ocean biogeochemistry is that only about half the inventory of dissolved nitrate and phosphate is directly associated with carbon. This can easily be seen by considering the inventories of phosphate and oxygen in the deep ocean. The ratio of phosphate remineralization to oxygen utilization is around 1:170 for the deep ocean, but the average apparent oxygen utilization is only of order $170 \mu \mathrm{M}$. Thus only about $1 \mu \mathrm{M}$ of the phosphate in the deep ocean is associated with remineralized carbon. Since the concentration of phosphate in the deep ocean is $2.2 \mu \mathrm{M}$, then approximately half of it is not associated with carbon. This biologically unutilized phosphate reaches the deep as a result of surface waters that subduct with high nutrient content and is known as preformed phosphate, or $\mathrm{PO}_{4}^{\text {pref }}$.

Because the micronutrient Fe is used for both chlorophyll synthesis and nitrate reduction, both of which are vital for plankton growth (cf. Boyd 2002), much attention has been focused on iron limitation as a mechanism to explain the relatively high oceanic concentrations of $\mathrm{PO}_{4}^{\text {pref }}$. The promise of ocean iron fertilization (OIF) is that shifting nutrients from the biologically unutilized (or preformed) pool to the biologically uti- lized (or remineralized) pool allows the ocean to hold more carbon. This carbon will be taken out of the atmosphere. A schematic illustration of how this might work is given in Fig. 1a, which shows how increased productivity and export leads to a reduction in nutrients subducting to depth.

It is common in discussions about OIF for an equivalence to be made between increased nutrient utilization and increased particle export. One of the points of this paper is to reiterate that such a connection need not hold. To take an obvious example, if water is flowing through a region where $20 \%$ of the nutrients are stripped out, a faster flow of water through the region will lead to a larger export, even though the fraction of nutrient utilized remains constant. A subtler example is shown in Fig. 1b, where iron fertilization causes nutrients to be consumed locally at point $\mathrm{A}$, so that fewer nutrients are advected (on time scales of years to centuries) downstream to point $\mathrm{B}$. This can result in a decrease in export, not only at point B, but also globally (Marinov et al. 2006). But since the average global concentration of preformed nutrients into the deep ocean drops, so does atmospheric carbon dioxide. A final case (Fig. 1c) is one in which nutrients are consumed before subduction. By concentrating production near the upwelling, fertilization may then produce 
Scenario Unperturbed case
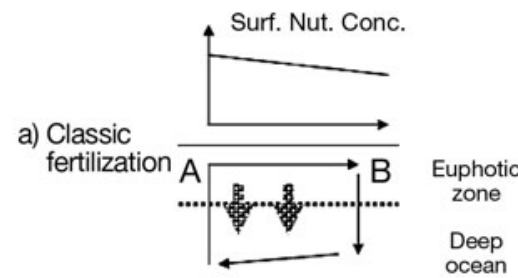

Fertilization case (at location A)
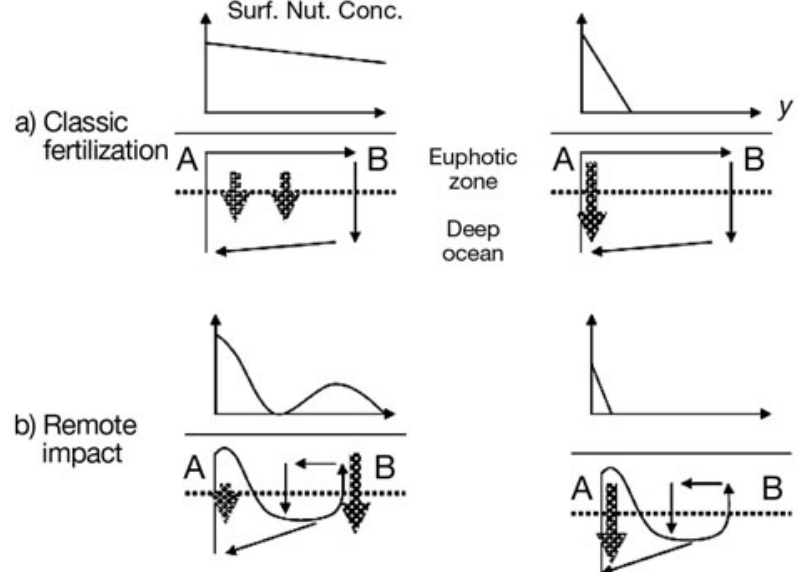

Export increases as more nutrients are consumed, preformed nutrient concentrations, and thus atmospheric

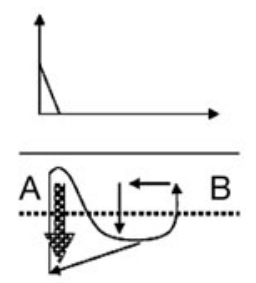

Global export can actually drop as drops, but preformed nutrient concentrations, and thus atmospheric $\mathrm{pCO}_{2}$ levels drop

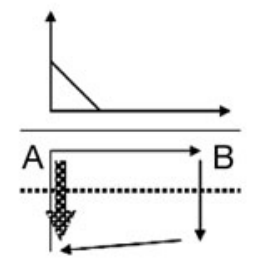
$\mathrm{pCO}_{2}$ levels drop downstream production

$$
\overline{\mathrm{PO}_{4}^{\text {remin }}}=\overline{\mathrm{PO}_{4}^{\text {tot }}}-\overline{\mathrm{PO}_{4}^{\text {pref }}}
$$

where $\overline{\mathrm{PO}_{4}^{\text {tot }}}$ is the total phosphate content and $\mathrm{PO}_{4}^{\text {pref }}$ is the globally averaged $\mathrm{PO}_{4}^{\text {pref }}$, i.e. that associated with subducting waters. The biological oceanic carbon storage then consists of a term proportional to remineralized phosphate and a term associated with disequilibrium $\left(\mathrm{OCS}_{\text {bio }}^{\text {diseq }}\right)$, resulting from the fact that ocean water depleted in carbon by biological production (or enriched by upwelling of carbon rich deep waters) may not have time to come into equilibrium with the atmosphere before it is subducted. We focus on phosphate rather than nitrate for 2 reasons, the first being that its longer residence time and lack of nitrification/denitrification feedbacks makes it more likely to be the ultimate limiting nutrient (Tyrrell 1999, Moore \& Doney 2007), and the second being that C:P ratios appear to be much more variable than $\mathrm{C}: \mathrm{N}$ ratios.

This basic picture can be used to analyze why different ocean models produce different atmospheric $\mathrm{pCO}_{2}$ $\left(\mathrm{pCO}_{2}^{\mathrm{atm}}\right)$. Marinov et al. $(2008 \mathrm{a}, \mathrm{b})$ examine a range of diagnostic ocean models using a simple representation of biological cycling in which nutrient concentrations near the surface are restored either to the observed value to mimic the natural carbon cycle or to 0 to mimic the maximum possible effects of OIF. This must be understood as an upper limit, as both large-scale (100s of $\mathrm{km}$ ) natural fertilization patches associated with topographic features (cf. Pol'nutrient trapping' (Najjar et al. 1992), increasing the concentration of upwelling nutrients and so resulting in a net increase in production, but without significantly changing preformed nutrients and atmospheric $\mathrm{CO}_{2}$ (as noted in Aumont \& Bopp 2006).

Recent work by Marinov et al. (2008a) suggests a more productive way to think about the oceanic carbon storage associated with biology $\left(\mathrm{OCS}_{\mathrm{bio}}\right)$. Disregarding for the present the smaller calcium carbonate pump,

$$
\mathrm{OCS}_{\text {bio }}={\overline{\mathrm{PO}_{4}^{\text {remin }}}}_{\mathrm{R}_{\mathrm{C}: \mathrm{P}}+\mathrm{OCS}_{\text {bio }}^{\text {diseq }}}
$$

where $\overline{\mathrm{PO}_{4}^{\text {remin }}}$ is the globally averaged remineralized phosphate in the ocean, and $\mathrm{R}_{\mathrm{C}: \mathrm{P}}$ is the $\mathrm{C}: \mathrm{P}$ ratio and can be written as lard et al. 2007) and mesoscale (10s of km) purposeful experiments (Boyd et al. 2007) only show drawdowns between 30 and $75 \%$ of the initial nutrient inventory. In these models, $R_{C: P}$ is set to a constant value of 117 for all time and space. By using a set of models in which the winds and diffusion coefficients differ, we are able to examine the extent to which the response of $\mathrm{pCO}_{2}^{\text {atm }}$ to nutrient drawdown depends on the global overturning circulation.

One result that has emerged from these models is that changes in circulation can change $\mathrm{pCO}_{2}^{\text {atm }}$ by changing $\overline{\mathrm{PO}_{4}^{\text {pref }}}$ (Marinov et al. 2008a). This can be seen in Fig. 2a, which shows results from the control set of the model, where surface nutrients are restored to observed values. As the preformed nutrients 

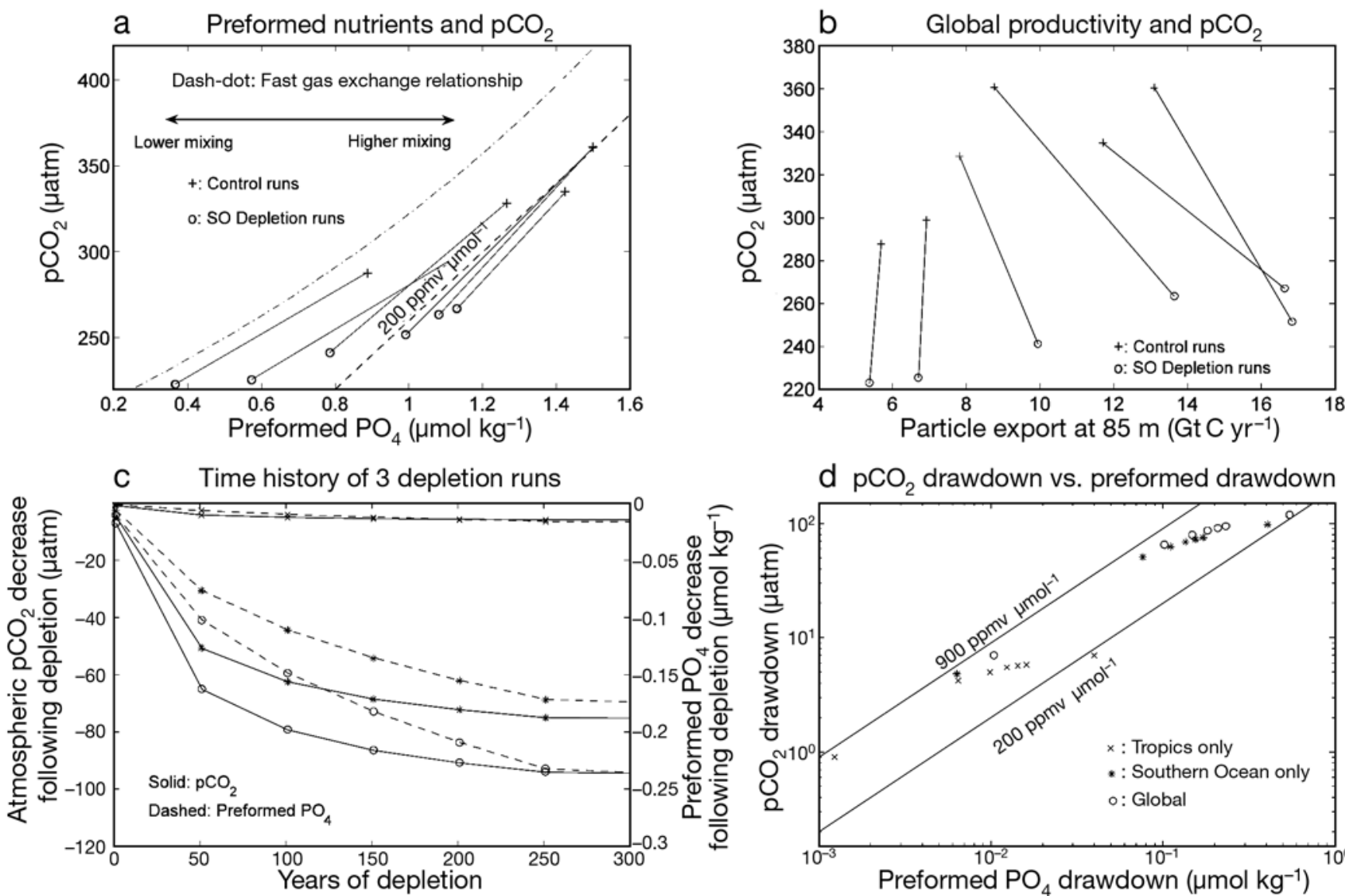

d $\mathrm{pCO}_{2}$ drawdown vs. preformed drawdown

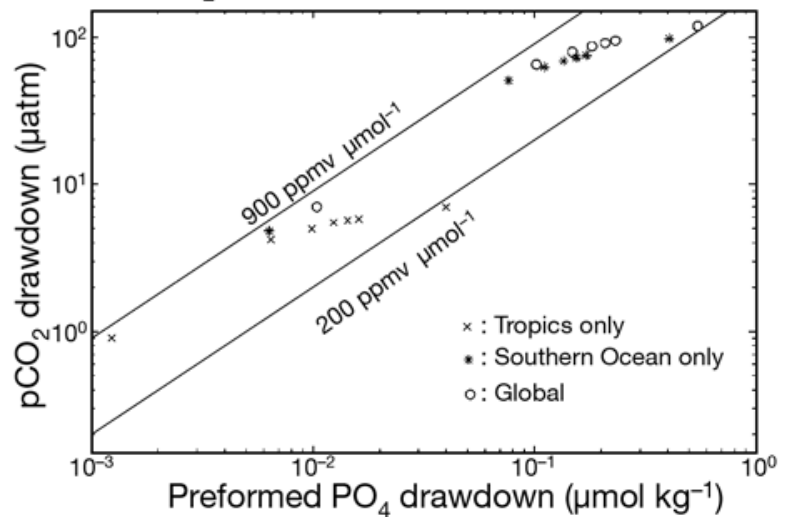

Fig. 2. Results from a number of models in which nutrients are restored to 0 over some area, illustrating the importance of preformed nutrients in understanding the carbon cycle. Runs are made with coarse-resolution, $4^{\circ}$ models following Gnanadesikan et al. (2004) and Marinov et al. (2006, 2008a,b), with different horizontal and vertical mixing coefficients and wind stresses. (a) Atmospheric $\mathrm{pCO}_{2}$ versus globally averaged preformed nutrient concentration for 6 different models. Control runs are shown by (+), runs in which Southern Ocean nutrients are restored towards 0 by (o). (b) Same as (a), but with particle export at $85 \mathrm{~m}$ as the independent variable. Note the slope is strongly dependent on the intensity of vertical exchange. (c) 3 simulations with the P2A model (Marinov et al. 2006), in which nutrients are restored to 0 globally (O), over the Southern Ocean (*) and over low latitudes ( $\times$ ). Solid lines show atmospheric $\mathrm{pCO}_{2}$ change, dashed lines the change in preformed phosphate. Note the bulk of the difference in atmospheric $\mathrm{pCO}_{2}$ between runs can be explained in terms of the corresponding difference in preformed phosphate. (d) Absolute change in $\mathrm{pCO}_{2}$ plotted against preformed phosphate for the runs in Fig. 1c, at 1, 51, 101, 151, 201 and 251 yr, as well as at equilibrium. Note the values start close to the theoretical slope and move rightward over time as the role of chemical buffering increases

decrease (implying that remineralized nutrients increase) because of lower vertical mixing, so does $\mathrm{pCO}_{2}^{\mathrm{atm}}$. When nutrients are restored to 0 in the Southern Ocean (Fig. 2a, O-marks) the preformed nutrients decrease significantly and so does $\mathrm{pCO}_{2}^{\mathrm{atm}}$. The dashdotted line in Fig. 2a shows the exponential relationship between the two, derived by Marinov et al. (2008b) under the limit of infinitely fast gas exchange.

How would we expect $\mathrm{pCO}_{2}^{\mathrm{atm}}$ to respond to changes in preformed phosphate? Decreasing $\overline{\mathrm{PO}_{4}^{\text {pref }}}$

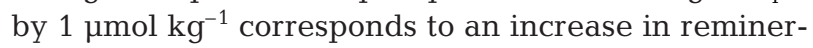
alized carbon of about 1940 Gt C, given an ocean volume of $1.345 \times 10^{18} \mathrm{~m}^{3}$. If all of this carbon came out of the atmosphere, it would draw down atmospheric $\mathrm{CO}_{2}$ by 900 ppmv. However, the actual response in the models is about $20 \%$ of this, between 150 and
200 ppmv $\mu_{\mathrm{mol}^{-1}} \overline{\mathrm{PO}_{4}^{\text {pref }}}$ depending on the model employed. Note that some of the models on the left of Fig. $2 b$ show a global decrease in production even though $\mathrm{pCO}_{2}^{\mathrm{atm}}$ drops, just as suggested in Fig. 1b.

This smaller-than-expected response is due to chemical buffering. Suppose the circulation changes so as to increase preformed nutrients. Much of the carbon pushed out of the ocean by such a change will eventually (over centuries) end up in the ocean as it reacts with ionic carbonate - just as most anthropogenic carbon added to the atmosphere today will eventually end up in the ocean. Conversely, much of the carbon that is initially removed from the atmosphere by fertilization will eventually return to the atmosphere.

Within this picture, OIF could increase $\overline{\mathrm{PO}_{4}^{\text {remin }}}$ (Eq. 1) in 3 ways: (1) Increasing $\overline{\mathrm{PO}_{4}^{\text {remin }}}$ (or decreasing $\overline{\mathrm{PO}_{4}^{\text {pref }}}$ ) 
by increasing photosynthetic uptake and the subsequent remineralization of organic matter. Nutrients which would have gone into the deep ocean as unutilized/preformed are now in the remineralized pool instead. (2) Increasing $R_{\text {C:P }}$ i.e. making nutrient uptake more efficient at sequestering carbon. There is extensive evidence that the C:P ratio in plankton may vary, in large part due to variations in the N:P ratio (Letelier \& Karl 1996, Klausmeier et al. 2004). (3) Increasing OCS $_{\text {bio }}^{\text {diseq }}$ by making it harder for remineralized carbon to escape from the ocean. This will occur if fertilization redistributes remineralized carbon such that more of it comes to the surface in regions where it does not have time to equilibrate with the atmosphere.

In the following sections we consider some of the complications associated with each of these 3 mechanisms. Before doing so we note that the preformed nutrient content is essentially independent of the depth of remineralization, so long as one considers an equilibrium situation. If phosphorus is associated with carbon and iron it does not matter substantially whether it is remineralized at $200 \mathrm{~m}$ or $2000 \mathrm{~m}$, in either case it acts to sequester carbon. Thus, Sarmiento \& Orr (1991) found that the response to a perpetual fertilization in the Southern Ocean was essentially independent of the depth of remineralization and Gnanadesikan et al. (2003) found a similar result for addition of a 'supernutrient' that permanently increased $\overline{\mathrm{PO}}_{4}^{\text {remin }}$. If the changes are transient, however, remineralization depth may be important, as it determines the time over which the changes persist.

\section{CHANGING REMINERALIZED PHOSPHATE AND RESULTING COMPLICATIONS}

One simple means of estimating the potential effects of OIF on the carbon cycle is to assume that it will lead to a drawdown of surface nutrients and to then see how such changes propagate through the system. This was the approach taken by Sarmiento \& Toggweiler (1984) in a box model study of fertilization and in studies made using general circulation models by Sarmiento \& Orr (1991), Archer et al. (2000), Gnanadesikan et al. (2003) and Marinov et al. (2006, 2008a,b), among others. While neglecting ecosystem effects and feedbacks through the nitrogen cycle, such an approach does provide a useful means of assessing the potential timescales involved in carbon cycle changes resulting from fertilization and the magnitude of such changes.

We present results from 3 such simulations in our standard (so-called P2A) ocean model, which corresponds to nutrient drawdown in the tropics only, south of $30^{\circ} \mathrm{S}$ only, and globally (Fig. 2c,d). Thinking about the evolution of these runs in terms of changes in pre- formed nutrients yields some clear insights into their behavior. For example, the much lower effect of drawing down nutrients in the tropics on $\mathrm{pCO}_{2}^{\text {atm }}$ is due to the much smaller effect on globally averaged preformed nutrient. The bulk of the atmospheric $\mathrm{CO}_{2}$ drawdown comes from fertilizing the Southern Ocean (as noted by Marinov et al. 2006), where the effect on preformed nutrients is largest. When preformed nutrient changes are plotted against atmospheric $\mathrm{CO}_{2}$ changes, however (Fig. 2d), the picture is much more similar across the simulations. Initially, the bulk of the carbon dioxide comes out of the atmosphere and so the drawdown is more like the idealized $900 \mathrm{ppmv}^{\mathrm{m} \mathrm{mol}^{-1}}$ $\mathrm{PO}_{4}^{\text {pref }}$. This continues for 50 to $100 \mathrm{yr}$. However, over time (centuries), chemical buffering becomes important and the final equilibrium slope lies within the range of slopes seen in Fig. 1a. If one looks at the ratio between the change in $\overline{\mathrm{PO}_{4}^{\text {pref }}}$ and the change in $\mathrm{pCO}_{2}^{\text {atm }}$ (not shown), the 3 simulations collapse to within about $20 \%$ of each other.

To a large extent, then, changes in $\overline{\mathrm{PO}_{4}^{\text {pref }}}$ or $\overline{\mathrm{PO}_{4}^{\text {remin }}}$ are a good metric for evaluating the effect of OIF on $\mathrm{pCO}_{2}^{\mathrm{atm}}$. This raises a number of important issues when considering the impact of local fertilization. The first issue is that fertilization may not result in a net change in $\overline{\mathrm{PO}_{4}^{\text {remin }}}$ if the nutrients taken up would have been used at some later time or some different location. An example of this can be found in the highly idealized results of Gnanadesikan et al. (2003), which examined the response in a diagnostic ocean model to reducing the target nutrient concentration in a region to zero for a single month over a small patch. Because of the parameterization of production in terms of a restoration to some value, the increased drawdown of nutrients during a fertilization event was largely balanced by decreased production in the following months as nutrients recovered to their pre-fertilization values. As a result, the net decrease in unutilized nutrients was relatively small, with only 2 to $7 \%$ of the net additional production during the fertilization event resulting in $\mathrm{pCO}_{2}^{\text {atm }}$ drawdown.

It must be emphasized, however, that this case is an extreme one. Essentially the assumption made in Gnanadesikan et al. (2003) is that once fertilization stops the system will return surface nutrients to pre-fertilization levels on a short time scale, something that is unlikely to be true. However, the simulation does highlight the potential importance of post-fertilization declines in productivity. Such declines were observed by Aumont \& Bopp (2006), Jin et al. (2008), and J. L. Sarmiento et al. (unpubl. data), using 3 different biogeochemical models in which fertilization was applied for a relatively short time period $(<10 \mathrm{yr})$, then abruptly stopped. The drops in export production across $100 \mathrm{~m}$ are not nearly as large as in the idealized case, but are potentially significant nonetheless, accounting for as much as 
one-third of the initial production. Aumont \& Bopp (2006) attributed the change to a drop in surface nutrient content. J. L. Sarmiento et al. (unpubl. data) found that this drop is due to enhanced denitrification.

In Gnanadesikan et al. (2003), nutrient drawdown was ineffective at sequestering carbon because productivity at the time of fertilization was essentially 'borrowed' from productivity at some time in the future. The displacement of productivity may also happen in the vertical. Jin et al. (2008) found that the greater the depth at which fertilization enhances productivity, the smaller the effect on $\mathrm{pCO}_{2}^{\mathrm{atm}}$. They argue that this occurs because there is less separation between the low $\mathrm{pCO}_{2}$ anomaly resulting from productivity and the high $\mathrm{pCO}_{2}$ anomaly resulting from remineralization so that these anomalies are able to cancel each other out before contacting the atmosphere. However, Gnanadesikan (2007) notes that Jin et al. (2008) also found a decrease in productivity near the surface, compensating for the increase in export at depth. This would act to decrease remineralized nutrients, resulting in no net change in biological carbon storage.

\section{CHANGING $\mathbf{R}_{\mathrm{C}: \mathrm{P}}$ AND RESULTING COMPLICATIONS}

There are a number of reasons to believe that OIF could cause changes in the ratio of carbon to phosphate. Higher C:P ratios have been found for nitrogen fixers (Letelier \& Karl 1996) which can be limited by iron (Mills et al. 2004). Hoffman et al. (2006) found an increase in the C:P ratio of micro-, nano-, and picoplankton during the European Iron Fertilization Experiment (EIFEX). They hypothesize that iron-limited plankton cannot build nitrate reductase and so will tend towards low N:P ratios and (assuming constant $\mathrm{C}: \mathrm{N}$ ratio), low $\mathrm{C}: \mathrm{P}$.

The great advantage of achieving carbon sequestration through changing the $\mathrm{C}: \mathrm{P}$ ratio in sinking organic matter is that it would be much easier both to evaluate the impact and to monitor the persistence of the effect by measuring nutrients in situ. Examination of Eq. (1) shows that a $10 \%$ increase in $\mathrm{R}_{\mathrm{C}: \mathrm{P}}$ would be expected to have the same effect on $\mathrm{pCO}_{2}^{\mathrm{atm}}$ as a $10 \%$ increase in $\overline{\mathrm{PO}_{4}^{\text {remin }}}\left(0.1 \mu \mathrm{mol} \mathrm{kg}{ }^{-1}\right.$, implying a decrease of $20 \mathrm{ppmv}$ at equilibrium) and far larger variations than this are seen in some regions.

There are, however, some serious complications involved in considering the effect of changing stoichiometric ratios on atmospheric carbon. The most important is that $\mathrm{R}_{\mathrm{C}: \mathrm{P}}$ may go down as well as up with OIF. Arrigo et al. $(1999,2002)$ point out that $\mathrm{R}_{\mathrm{C}: \mathrm{P}}$ associated with nutrient drawdown is much larger in regions of the Antarctic dominated by phaeocystis blooms $\left(\mathrm{R}_{\mathrm{C}: \mathrm{P}}\right.$ of 120 to 154) compared with regions dominated by diatoms $\left(\mathrm{R}_{\mathrm{C}: \mathrm{P}}\right.$ between 62 and 100). Additionally, recent work by Klausmeier et al. (2004) observes that the $\mathrm{N}: \mathrm{P}$ ratio in plankton varies from 8 to 42 over a range of regimes. They argue that in a regime where the plankton are seeking to acquire resources (light and nitrogen) they will tend to build cellular machinery rich in $\mathrm{N}$ relative to $\mathrm{P}$ and that they will have high $\mathrm{N}: \mathrm{P}$ (and thus presumably high $\mathrm{C}: \mathrm{P}$ ) ratios, while rapidly growing cells require more ribosomal material with more $\mathrm{P}$ and so will have low N:P (and C:P) ratios.

The effects of OIF on community structure and phytoplankton physiology thus add an additional level of complication. Replacing carbon-rich phaeocystis blooms with carbon-poor diatom blooms would (according to Eq. [1] and assuming $\overline{\mathrm{PO}_{4}^{\text {remin }}}$ is constant) drive ocean carbon storage down and $\mathrm{pCO}_{2}^{\mathrm{atm}}$ up. Similarly, if phytoplankton have high $\mathrm{C}: \mathrm{P}$ ratios because they are limited by light, adding iron to remove light limitation could reduce C:P ratios and cause $\mathrm{pCO}_{2}^{\mathrm{atm}}$ to rise. But if the addition of iron caused an increase in the ability to acquire nutrients (say, for example, through allowing nitrogen fixation or shifting the population towards nitrogen fixers as discussed by Moore \& Doney 2007) C:P ratios could increase, causing $\mathrm{pCO}_{2}^{\mathrm{atm}}$ to fall. Such processes are only represented in current ocean ecosystem models at a rudimentary level.

\section{INCREASING THE EFFICIENCY OF GAS EXCHANGE}

Gas exchange can play a role in altering the storage of carbon in the ocean. This can clearly be seen in Fig. 2a from the difference between the theoretical curve with infinitely fast exchange and the simulations with normal gas exchange. Under infinitely fast gas exchange all the points in Fig. 2a lie on the theoretical curve (Marinov et al. 2008b) and $\mathrm{OCS}_{\text {bio }}^{\text {diseq }}=0$. With realistic gas exchange, however, $\mathrm{OCS}_{\text {bio }}^{\text {diseq }}$ is nonzero. If remineralized nutrients are brought to the surface, converted to preformed nutrients and rapidly (i.e. on time scales of weeks to months) reinjected to the deep before biology or gas exchange can act on them, the conversion of $\overline{\mathrm{PO}_{4}^{\text {remin }}}$ to $\overline{\mathrm{PO}_{4}^{\text {pref }}}$ will occur without a corresponding change in carbon. $\mathrm{OCS}_{\text {bio }}^{\text {diseq }}$ will be $>0$ because there is no loss of $\mathrm{CO}_{2}$ to the atmosphere and the biological pump will be more efficient at storing carbon than nutrient fields alone would indicate. This will be particularly the case in convective regions of deep water formation (Toggweiler et al. 2003). Alternatively, one can imagine a case where nutrients are brought to the surface, advected along the surface and taken up by biology just before (weeks or months) they are downwelled. In such a case, the lowered $\mathrm{CO}_{2}$ associated with enhanced production would not have time 
to come to equilibrium with the atmosphere, and the biological pump would be less efficient at storing carbon than the nutrient fields would indicate $\left(\mathrm{OCS}_{\text {bio }}^{\text {diseq }}<0\right)$.

In all of the runs we have done so far, the first mechanism is the most important and $\mathrm{OCS}_{\text {bio }}^{\text {dise }}>0$ (compare all points with the dash-dotted line in Fig. 2a). The net effect of gas exchange on OIF is more complicated. In some of the runs (those associated with higher mixing and higher preformed nutrients), the disequilibrium term increases under depletion. In other runs (those associated with lower mixing and lower preformed nutrients) the disequilibrium term decreases under depletion. These changes can enhance or compensate for 10 to $20 \%$ of the $\mathrm{pCO}_{2}^{\mathrm{atm}}$ change associated with changing $\overline{\mathrm{PO}_{4}^{\text {pref }}}$.

\section{CONCLUSIONS}

The extent to which the export of organic material from the surface ocean results in oceanic carbon storage is not simply controlled by the magnitude of the export flux or the depth of remineralization. Rather, it depends on the extent to which nutrients in the deep ocean are associated with carbon and the extent to which this carbon is able to escape from the deep ocean. As a result, local balances are unlikely to describe the global impact of OIF. Effects remote from the fertilization site in time (months to centuries) or space $(100 \mathrm{~s}$ to $1000 \mathrm{~s} \mathrm{~km})$ - such as reduction in productivity, changes in stoichiometric ratios or changes in the disequilibrium of sinking water - can significantly affect the impact of OIF on atmospheric carbon dioxide. Understanding these effects and constructing models that accurately represent them is thus a crucial part of designing large-scale OIF projects.

Acknowledgements. The authors thank M. Westley, R. Toggweiler, M. Hiscock, P. Boyd and an anonymous reviewer for careful reviews of this paper; J. Sarmiento for useful discussions, and R. Slater for help in setting up the experiments.

\section{LITERATURE CITED}

Archer DE, Eshel G, Winguth A, Broecker W, Pierrehumbert $\mathrm{R}$, Tobis M, Jacob R (2000) Atmospheric $\mathrm{pCO}_{2}$ sensitivity to the biological pump in the ocean. Global Biogeochem Cycles 14:1219-1230

Arrigo KR, Robinson DH, Worthen DL, Dunbar RB, DiTullio GR, Vanwort M, Lizotte MP (1999) Phytoplankton community structure and the drawdown of nutrients and $\mathrm{CO}_{2}$ in the Southern Ocean. Science 283:365-367

Arrigo KR, Dunbar RB, Lizotte M, Robinson DH (2002) Taxonspecific differences in C/P and N/P drawdown for phytoplankton in the Ross Sea, Antarctica. Geophys Res Lett 29:1938

> Aumont O, Bopp L (2006) Globalizing results from ocean in situ iron fertilization studies. Global Biogeochem Cycles 20:GB2017

Boyd PW (2002) Environmental factors controlling phytoplankton processes in the Southern Ocean. J Phycol 38:844-861
Boyd PW, Jickells T, Law CS, Blain S and others (2007) Mesoscale iron enrichment experiments 1993-2005: synthesis and future directions. Science 315:612-617

Gnanadesikan A (2007) Interactive comment on 'The impact on atmospheric $\mathrm{CO} 2$ of iron fertilization induced changes in the ocean's biological pump'. Biogeosciences Discuss 4: S2042-S2048

Gnanadesikan A, Sarmiento JL, Slater RD (2003) Effects of patchy ocean fertilization on atmospheric carbon dioxide and biological production. Global Biogeochem Cycles 17: 1050, doi:10.1029/2002GB001940

Gnanadesikan A, Dunne JP, Key RM, Matsumoto K, Sarmiento JL, Slater RD, Swathi PS (2004) Oceanic ventilation and biogeochemical cycling: understanding the physical mechanisms that produce realistic distributions of tracers and productivity. Global Biogeochem Cycles. 18: 4010, doi:10.1029/2003GB002097

Hoffman LJ, Peeken I, Lochte K, Assmy P, Veldhuus M (2006) Different reactions of Southern Ocean phytoplankton sizes to iron fertilization. Limnol Oceanogr 51:1217-1229

Jin X, Gruber N, Frenzel H, Doney SC, McWilliams JC (2008) The impact on atmospheric $\mathrm{CO}_{2}$ of iron fertilization induced changes in the ocean's biological pump. Biogeosciences 5:385-406

Klausmeier CA, Litchman E, Daufresne T, Levin SA (2004) Optimal nitrogen-to-phosphorus stoichiometry of phytoplankton. Nature 429:171-174

Letelier RM, Karl DM (1996) Role of Trichodesmium spp. in the productivity of the subtropical North Pacific Ocean. Mar Ecol Prog Ser 133:263-273

Marinov I, Gnanadesikan A, Sarmiento JL, Slater RD (2006) The Southern Ocean biogeochemical divide. Nature 441: 964-967

Marinov I, Gnanadesikan A, Mignone BK, Toggweiler JR, Sarmiento JL, Slater RD (2008a) Impact of oceanic circulation on biological carbon storage in the ocean and atmospheric $\mathrm{CO}_{2}$. Global Biogeochem Cycles (in press)

Marinov I, Follows MJ, Gnanadesikan A, Sarmiento JL, Slater RD (2008b) Atmospheric $\mathrm{pCO}_{2}$ sensitivity to surface nutrient depletion in the ocean-theory and models. J Geophys Res (in press)

Mills MM, Ridame C, Davey M, La Roche J, Geider RJ (2004) Iron and phosphorus colimit nitrogen fixation in the eastern tropical North Atlantic. Nature 429:292-294

> Moore JK, Doney SC (2007) Iron availability limits the ocean nitrogen inventory stabilizing feedbacks between marine denitrification and nitrogen fixation. Global Biogeochem Cycles 21:GB2001

> Najjar RG, Sarmiento JL, Toggweiler JR (1992) Downward transport and fate of organic matter in the ocean: simulations with a general circulation model. Global Biogeochem Cycles 6:45-76

Pollard R, Sanders R, Lucas M, Statham P (2007) The Crozet Natural Iron Model and Export Experiment (CROZEX). Deep-Sea Res II 54:1905-1914

Sarmiento JL, Orr JC (1991) Three-dimensional simulations of the impact of Southern Ocean nutrient depletion on atmospheric $\mathrm{CO}_{2}$ and ocean chemistry. Limnol Oceanogr 36:1928-1950

Sarmiento JL, Toggweiler JR (1984) A new model for the role of the oceans in determining atmospheric $\mathrm{pCO}_{2}$. Nature 308:621-624

> Toggweiler JR, Murnane RJ, Carson SC, Gnanadesikan A, Sarmiento JL (2003) The strengths of carbon pumps in box models, GCMs and the real world. II. The biological pump. Global Biogeochem Cycles 17:1027

Tyrrell T (1999) The relative influences of nitrogen and phosphorus on oceanic primary production. Nature 400: 525-531 